\title{
Declientification: Undoing Client Identities in Care Planning Conferences on the Termination of Residential Care
}

\author{
Heinz Messmer and Sarah Hitzler
}

Heinz Messmer is a professor for social work and child welfare at the University of Applied Sciences North Western Switzerland. He holds his Doctor of Sociology from Bielefeld University and habilitated with a work on social conflict. His recent research interests focus on institutions of child welfare, social work practice and conversation analysis. Sarah Hitzler is a faculty member at the Department of Sociology at Bielefeld University, Germany. She holds an M.A. degree in Discourse and Argumentation Studies from Amsterdam University, and has recently completed her doctoral thesis on discourse management in care planning conferences. Her research interests lie in the fields of conversation analysis, group interaction and practices in aid and welfare institutions.

Correspondence to Prof. Dr Heinz Messmer, University of Applied Sciences, North Western Switzerland, Thiersteinerallee 57, CH-4053 Basel, Switzerland. E-mail: heinz. messmer@fhnw.ch

\begin{abstract}
That social welfare clients ought to be looked at not as given, a priori entities, but rather as categories produced in accordance with the policies, resources and options of the institutions involved is established today as a common ground for reflexive and reconstructivist perspectives in social work research. The disestablishment of the client role, however, up to now seems to have met a blind spot. This article will present findings from a conversation analytical study based on fourteen fully transcribed care planning conferences in the context of German long-term residential childcare, concentrating on five meetings explicitly designed to terminate the service provision. We will show how long-term residential care is regularly terminated by a range of interactional strategies complementary to those of client production that can be flexibly exploited in response to institutional and political context requirements. Conversation analysis is introduced as a method that can unveil the interactive practices professionals use in order to balance the constraints of institutional social work against the needs of the individual cases.
\end{abstract}

Keywords: Care planning conference, child welfare, client identity, conversation analysis, leaving care, professional/client interaction

Accepted: March 2011 


\section{Leaving care}

Leaving care is an issue little considered from a processual perspective. The past fifteen years have seen some discussion on young people's discharge from care systems triggered mostly by the observation that youth with a care background tend to have significantly fewer chances of integration into society than do adolescents from intact family backgrounds (Stein, 2006). An awareness is growing internationally that 'young people leaving care are arguably one of the most vulnerable and disadvantaged groups in society' (Mendes and Moslehuddin, 2004, p. 332) and that the transition into a new and demanding life phase needs to be carefully planned and supported (Maunders et al., 1999; Stein, 2006). The transition from care into independence tends to be earlier, less well prepared, more abrupt and more definite than transitions out of family contexts, while, at the same time, the young people have fewer social and individual resources to fall back on (West, 1995). This fact leads scholars to describe it as an instance of 'careism', that is, the systematic discrimination of individuals in care as compared to individuals leading lives closer to the societal normative ideals (Lindsay, 1994; Maunders et al., 1999). As the common notion of 'leaving care' suggests, such research has mostly concentrated on what happens to clients after they have exited the youth welfare system. While some criticism is directed at the fact that care is often terminated at a considerably early age of the clients (Stein, 2005), no insights are provided into what political, institutional and interactive mechanisms gear the processes eventually leading to termination.

In the context of German social work research, the leaving care debate has been strongly neglected. Both theory and empirical research appear to rely on the assumption that whatever happens when the relationship of support between professionals and their clients is brought to an end is obvious and does not require further examination. The prevailing idea seems to be that termination of care is no more than a logical consequence of the successful completion of professional tasks. Since child and youth welfare, however, was made a legal entitlement in Germany at the beginning of the 1990s, considerations external to mere success have increasingly affected decisions on the termination of welfare provisions. Increasing costs have pushed the municipalities to their financial limits. In reaction, youth welfare agencies have been attempting to resort to seemingly objective limitations such as the age of their clients, using them as gate-keeping variables (Erickson and Schultz, 1982) in order to regulate the demand and access regarding cost-intensive service delivery. While official statistics clearly show that young adults often are in need of continued state support, the youth welfare agencies seem to adhere to rather restrictive politics out of fiscal considerations (Sandermann et al., 2007; Wiesner, 2007). Correspondingly, there is a clear preference for local and ambulatory 
service provision, while long-term and more expensive solutions are predominantly resorted to only when these have conclusively failed (Thiersch, 1999; Kurz-Adam et al., 2002; Messmer, 2007; for similar developments in Australia and the UK, see Mendes and Moslehuddin, 2004).

Thus, youth welfare workers inevitably get caught in conflicting developments. These affect in observable ways the practices of care planning: out of one hundred practitioners interviewed, more than half considered cost issues relevant for decisions (Modellprogramm, 2003). Furthermore, about half of the cases displayed no clear standards for the termination of a service provision (Modellprogramm, 2003, p. 28). In addition, no other phase of the planning procedure appears to be considered as difficult at its end: half of all practitioners interviewed judged the work accomplished during this phase as 'bad' or 'rather bad', while only 7 per cent described it as 'good' without reservations (Modellprogramm, 2003, p. 46). These findings are supported by a study by Baur et al. (2002, pp. 156-7), who find that, according to practitioners from youth welfare offices, less than half of their cases are brought to an end for professional reasons and in a scheduled way. Similarly, in her study on participation, Pluto (2007, p. 254) states: 'Realising participation with regard to the question as to when the support granted was enough, is a particular challenge for practitioners. The end of support..., other than its beginning, receives little professional attention' (authors' translation).

While all this indicates that social workers' decisions on the termination of residential care are not solely influenced by professional reasoning, up to now, no study has looked into how professionals deal with the interplay between context restrictions and the interactional needs within the relevant settings. This article will present findings regarding the question of how long-term residential care is regularly terminated by a range of interactional strategies that serve to turn the individual client into a mature and selfreliant citizen and that can be flexibly exploited in response to institutional constraints. Such interaction strategies will be subsumed under the heading 'declientification', referring to the interactionally required disestablishment of client identity necessary to terminating the welfare provision.

\section{Aims and methods of the study}

Care planning conferences can be described as recurrent group decisionmaking procedures (Hitzler and Messmer, 2010), which, by law, minimally involve a state social worker, a professional service provider and the client or clients. Together, the participants of such a meeting are to discuss and adjust educational service provision in individual cases. Care planning conferences therefore present themselves as sites of decision making in which professional and context premises of institutional action necessarily are 
confronted and can thus be seen as ideal sites for the analysis of professional strategies for managing the difficulties mentioned above.

Empirically, our study is based on audio-recordings of fourteen care planning conferences, recorded in four different institutions and covering four meetings from the beginning, five from the middle and another five from the termination stages of the service provisions. Participants to those conferences ranged from three to eight. Each of the audio-taped conferences lasted between forty and 130 minutes and was fully transcribed according to the prevailing transcript notations in German talk analytical studies (Selting et al., 1998). All participants gave their prior consent to the conferences' being audio taped for research purposes. Personal data (such as names of persons and places) were rendered unrecognisable in the transcripts of the talks.

The data excerpts used in this article have been carefully translated from the German original, with a focus on maintaining the gist of the interactions rather than sustaining the syntactical and lexical form. However, as every transcript is already an interpretive step removed from what originally happened (Bergmann, 1985), translation means a further step away from the original meaning, incorporating the translator's understanding of the sequence and restricted by their language proficiency (the issue of translated transcripts is discussed in depth by Nikander (2008)). We therefore can only ask readers to treat the insights we provide as attempts to closely illustrate the analytical work we have done on our data, while acknowledging that they are not identical to the analysis itself. The original excerpts will gladly be provided to interested readers. An overview of speaker identifiers and transcript notations can be found in the Annex.

Methodologically, our analyses are based on the principles of conversation analysis (CA). Stemming from ethnomethodology (Garfinkel, 1967), $\mathrm{CA}$ is grounded in the assumption that social reality is rule-bound and orderly as well as locally reproduced and intrinsically situated in the interactions of participants. It stands for a research perspective that understands social order as a systematically generated product of members in a society. That is to say that all social order is produced locally, in the ongoing stream of interactive dealings between individuals, and that it can only adequately be observed and described as such (Sacks, 1992).

Hence, CA follows a qualitative rather than quantitative stance, as attention is placed on precisely those factors of social action which are all-too-easily neglected or considered as irrelevant. One of the repeated findings of CA has been that it is the inconspicuous details and irregularities of members' activities that play a central role in the organisation of social order (cf., for instance, Sacks et al., 1974). Correspondingly, because of social actors' lack of reflection of their continuous efforts of establishing social reality, there is a deep mistrust in CA for ex post facto research such as ethnographic observation or interview studies. In contrast, the data that form the basis of CA ought to be as 'natural' as possible. 
The social situations investigated ought to have occurred in pretty much the same way had there not been an interested researcher to document them. The fundamental empirical unit is a single utterance (conversational turn) with which participants contribute to the locally produced social order-including such bothersome features as pauses, restarts or overlaps indicating the difficulties and obstacles that govern participants' talk (Jefferson, 2004).

Believing that their interactions serve as joint attempts to produce and reproduce an understandable social order that is accessible to any competent member of a speech community - that is, interactants and researchers alike-CA concludes that interactants themselves have to observe and analyse their ongoing activities and make these analyses interactively accessible to each other. Using each other's turns as context for the turns to follow, participants ensure mutual understanding and perpetuate the flow of the ongoing interaction, self-reflexively knitting a tight net of interactional meaning. Every utterance can thus be said to be 'context shaped' as well as 'context renewing', that is, to foreshadow meaning to come by drawing from meaning inferred (Heritage, 1984). Thus, the rule-bound grounds of orderly structured action can be detected and analytically reconstructed along the joint attempts of the participants involved.

We follow the CA's basic assumption that social reality is situated, rulebound and orderly, and, as such, produced and reproduced by participants communicating within a specific setting. In our analysis, we thus avoided formulating a priori categories or codes, rather working through our data sequentially and trying to identify characteristic interactional patterns. Therefore, we did not treat those instances of our corpus that dealt with the termination of welfare as different from the rest of the corpus but stumbled, when working through the data, upon interactional arrangements that struck us as distinct from, if not opposed to, what we could observe in other talks. Identifying these sequences and what was particular about them, we then managed to relate these to the larger context of those specific conferences and see that they were closely linked to the fact that all the talks that we had identified them in were geared at a discontinuation of ongoing care.

In this article, we aim to reconstruct, drawing from examples of this analysis, but not tracing in detail the inductive process of our analytical steps, the institutionally fuelled social order in care planning conferences on the termination of residential care referring to the interplay between context and interactions as (re)produced by the participants. We will start with a short discussion about the social production of client identities using results of our own empirical studies that can be used as contrast for the analyses of various declientification strategies that make up the core of this article. 


\section{The social production of clients}

When social work research turned towards reconstructivist and interactionbased perspectives, it soon came across the processes of client production as a part of the constitution of cases. The first talk-oriented studies (Bull and Shaw, 1992; Holstein, 1992) emphasised above all the practices of describing and classifying. Such practices are fundamental to the social production of clients, be it in face-to-face situations with the clients themselves (Antaki et al., 2002, Hall et al., 2003b) or in professional exchanges (Sarangi, 1998; Hall et al., 2006). The art of people processing (Hasenfeld, 1972) necessarily requires a transformation of individuals into clients (Lipsky, 1980; Cedersund and Säljö, 1994). As Hall et al. (2003a, p. 230) state, 'category negotiation is central to the practice of social work, not a precursor to it'.

In our own studies on care planning conferences, the social production of clients appeared to be a similarly central and recurrent issue. We could show how what we have termed clientification is realised in a turn-by-turn manner in accordance with the goals implied by the institutional setting (for a detailed account of our findings, see Messmer and Hitzler (2007)). We traced, for instance, how even the way of addressing a client will point to and consolidate their social identity and interactive status in a conference. In addition, by speaking about clients next to speaking with them, professionals achieve to objectify them in a way that factually excludes them from the ongoing interaction and leaves them mere on-lookers to the scenery. The core element of clientification, however, appears to us to be the establishment of a difference between actual and target states, where the actual state is characterised by a problem or deficit that serves to legitimate the implementation of a service provision, while the target state serves as a benchmark as to where the service provision should lead.

Focusing on the insight that client identities ought to be looked at not as given, a priori entities, but rather as categories produced in accordance with the policies, resources and options of the institutions involved, it seemed reasonable to suppose that similar strategies complementary to those of client production would become effective also in a reversal way.

\section{Declientification as an interactional accomplishment}

The anticipated termination of a service provision is usually brought into play some time before it becomes imminent. The older adolescent clients are, the more often that professionals mention during the course of a care planning conference that all youth welfare is necessarily temporary. This already points to a change in the institutional scheme. Closer examination of those talks in our corpus that are predominately concerned with the termination of support revealed in particular that these strategies material 
to client production in the initial stages of a service provision actually proceed in the opposite direction when it faces its end. According to these findings, terminating a service provision is no less complex and interactively challenging than is establishing it.

In the following, we present findings of our analyses on a number of care planning conferences explicitly designed to terminate residential care. We will argue that, prior to a final decision on the termination of residential care, professionals first have to disestablish the role of the client. Along the very lines of clientification, candidates for leaving care will have to be interactively produced by reversing previous clientification processes, thereby turning them into mature and self-reliant citizens instead. In the following sections, we will identify and highlight these patterns, showing that the termination of a service provision is a process marked by intricate communicative strategies and conflict-a process that also serves to shed light on the intrinsic ambiguities that characterise social work practice under the current policies.

\section{Removing interactional asymmetries}

While encounters between professionals and clients display a rather formal structure during the initial stages of service provision, termination conferences are marked by a noticeably informal stance of negotiation. Participants will not meet in official conference rooms, but rather gather in the living room of the children's home or in the client's living unit, thus allowing for a relaxed atmosphere. In addition, most talks are preceded by a lengthy sequence of small talk initiated by the professionals but mutually maintained, indicating familiarity between the participants. Similarly, in the course of termination conferences, the professionals will not strictly adhere to the structure underlying other talks, which is characterised by a more or less fixed sequential phasing (opening, report, discussion, decision, closing). Termination conferences actually lack a fully fledged report by the carer, which makes up a regular and extensive part of the talks in earlier stages. Assessments of the client's current development present themselves as a mixture of reproducing facts and fostering interpersonal relationships. This predominantly informal stance apparently serves to reduce the usual institutional asymmetries in a way that can notably change their status and role during the conference:

$\begin{array}{ll}\text { [1] } & \text { Lena 351-68 } \\ \text { CR: } & \text { what do you wanna talk about today; } \\ & \text { go ahead tell us in a word or two- } \\ (--) & \\ \text { CR: } & \text { [( ) }\end{array}$


CH: [(that's) my welfare is being abolished-

so-

HS: $\quad<<$ light laugh $>$ ( )bolished $->$

CR: [( )olished-

$\mathrm{CH}: \quad$ just cross it OUT and done;

HW: [yeah-

CR: cause it's YOUR care planning conference-

[you're of age after all-

HW: [so start again from the beginning;

the RIGHT way-

you want your welfare to be terminated.

[is that the way it is Lena-

CH: $\quad[<<$ drawn $>$ y:eah::.:.; $>$

$<$ quietly, hesitating $>$ no actually yes I do->

((continues))

This sequence in talk 'Lena' is preceded by a long stretch of mutual jokes and small talk, which is dominated by the professionals' mockery with regard to Lena's refrigerator. Laughter, co-operative communicative action as well as equal distribution of speaking rights point towards a friendly, informal atmosphere. In addition, the topics discussed reveal a longstanding, possibly amicable relationship between the participants. The sequence above in contrast can be understood as the formal opening of the official part of the conference. The familiar atmosphere and offhand style of communication are salvaged, however, and the allegedly serious topic of terminating an ongoing service provision is treated with light jocularity. Both Lena and the professionals, of course, know that her placement in a unit for assisted living is to be brought to an end, implying a substantial turning point in Lena's life. Nevertheless, both parties treat the subject in an ironic way. The carer's initial statement suggests that the upcoming topics are still open and of no particular relevance ('in a word or two-'); this understatement is taken up by Lena, who reacts by casting herself, in an obviously joking exaggeration, as the victim of external decisions ('my welfare is being abolished- (...) just cross it OUT and done;'); the head of the welfare office, in turn, challenges this interpretation by offering a reformulation that implies that it is she, not the professionals, who wants the service provision to be terminated ('the RIGHT way-you want your welfare to be terminated. is that the way it is Lena-').

The banter and irony obviously serve to palliate the difficult topic of leaving care (cf. Mik-Meyer, 2007; Osvaldsson, 2004). This topic is, however, treated with a high amount of anxiety by the clients in all of the conferences analysed, as shall be illustrated later. Of course, nothing less than their psychosocial support is at stake at a point of transition into a 
new and insecure life period. Instead of openly dealing with this fear, the participants choose to juggle with serious topics under the guise of symmetrical jocularity, allowing, at least temporarily, for status equality between the participants present. In addition, the carer's lexical choice explicitly singles out Lena as a crucial and adult member to the interaction ('you're of age after all-').

It can generally be stated that termination conferences are dominated by a different communicative style than are the other talks of our corpus. The professionals' bearing towards their clients is personal rather than affected by rigid institutional roles and the corresponding register is mostly intimate on both sides. In addition, the clients are repeatedly addressed directly (by 'speaking with') rather than treated as mere objects of communication (by 'speaking about') throughout our cases. This is no coincidence. As will become clear in the following, the adolescent clients are systematically treated as subjects capable of assuming personal responsibility rather than as objects of institutional action. Interactively treating a person as a mere 'case' would conflict with the actual intention of the conferencethe termination of the service provision. Indeed, the carer's phrase 'cause it's YOUR care planning conference - you're of age after all-' rhetorically reflects the content and the intention of the setting-making visible the autonomy and responsible individuality of a clientele outgrowing their role.

\section{Reducing the gap between the actual and target living conditions}

As sketched out above, the mechanisms of clientification are essentially characterised by careful construction of a difference between the actual and a target state of the client's life circumstances, which is usually expressed by some flaw, deficiency or problem, in short, by any description that makes visible a need for support (for a similar view, see Hydén, 1994). Declientification, in turn, is characterised by a levelling out of those exact differences. Negative categorisations are replaced by positive formulations regarding the clients' development, thereby revoking the orientation towards deficiencies. This entails the termination of the service provision: where there is no problem, there is no need for remedy. Consider a few more excerpts from Lena's conference:

[2] Lena 641-727 [excerpt with omissions]

CR: by now (.) she tidies up,

ALL by herself independently-

without $<<$ slight laugh $>$ my having $>$ to encourage her,

HS: $\mathrm{hm}=\mathrm{hm}-$

CR: $\quad$ fiNANcial stuff she'll settle independently with her BOY:friend, (-)

$(\ldots)$ 
CR: for example there's a whatsit-

a talk with her teacher is scheduled,

so Lena called me and made very clear-

I don't want you to be there?

beCAUse that's something I want to settle independently?

(...)

CR: she takes, (-)

right by now she assumes a great deal of personal responsibility-

now she merely NOtifies me of the things she does and deals with,

SW: $\quad h m=h m$,

CR: so it's NOT her calling me anymore and-

$<<$ hectically $>$.hh I have a problem- $>$

help me help me, $>$

but [she says-

CH: [ ( )-

CR: oh I was just going to inform you, (-)

I went to the- $(-)$

you called the $\mathrm{j}$ ahm jobcentre,

she ( ) social services-

she [did all that,

CH: $\quad[$ I'm $=$ getting fivehundred eighty Euros in all;

CR: solved everything all by herself,

HS?: ((silent laugh))

CR: and then only [notified me-

CH: [(but that's with the rent)-

CR: and I think that girl's taking a good PATH.

SW: yeah that's precisely what I see TOO;

CR: yeah-

Lena's carer has been asked, previously to this sequence, to report on her view of the girl's progress. While conditional relevance thus demands her speaking 'about' Lena, she still takes care (in accordance to the arguments above) to include her into the exchange, such as by switching addressees ('you called the $j$ ahm jobcentre, she ( ) social services - she [did all that') or by voicing Lena's position, quoting her directly. Where talking 'about' cannot be circumvented, symmetry is thus strived for differently.

Regarding the contents, as this excerpt clearly illustrates, the carer assesses Lena's recent development as positive throughout. The topics associated with this assessment touch upon issues such as tidiness and cleanliness, financial issues, Lena's independence and responsibility as well as 
her dealing with institutions such as school and the jobcentre. All these are issues that Lena was not able to address adequately before. Now, however, she is described as an independent and self-reliant person who does not need any more support with these fundamental parts of her everyday life. It is especially the repeated use of the temporal dimension in the carer's report ('by now') that highlights the difference between 'before' and 'now' regarding Lena's personal development. Similarly, the recurrent reference to her positive behavioural attributes ('by herself'; 'independently'; 'assumes personal responsibility') marks Lena's development as decidedly positive - a strategy that is still reinforced by a number of lexical intensifiers (cf. Brown and Levinson, 1987) such as 'ALL by herself'; 'made very clear'; 'a great deal of personal responsibility'. This collection of positive assessments leads to a clear conclusion, which the carer states right at the beginning of her remarks:

\section{[3] Lena 628-9}

CR: from my perspective, I can say very clearly-

Lena won't be needing youth welfare anymore,

We have found comparable patterns of positive evaluations even in cases in which a client's development clearly is considerably less favourable than Lena's. Consider Susanne, for example, who is twenty years old and so has already crossed the threshold of majority by two years. In describing her current situation, she talks about partial improvement in her overall living conditions, but also points to several constraints that she considers relevant: still unable to move among people free of fear, she is also uneducated and has no means of supporting herself financially while living a rather secluded life in her little apartment. She assesses being able to leave the house on her own as a slight improvement, which, however, is readily taken up and upgraded by the professionals:

[4] Susanne 134-55 (excerpt with omissions)

$\mathrm{CH}$ : that I:: (1.0) can go: to the doctor aLO:ne- (1.0)

go among people alone (.) more (--) now;

SW: $\quad h m=h m$,

CH: wasn't like that at all before really; (---)

I was afraid $<<$ slight laugh $>$ then right, $>$

(...)

SW: that really changed LOADS;

$\mathrm{CH}: \quad<$ curtly $>$ yup $->$

SW: [now you go- 
CH: [but not A:LL that-

.h ahm qui:te (-) ahm-

Susanne's account that she dares to mingle with people ('more (--) now'), which demonstrates her increased assertiveness, is taken up by the social worker, who repeats it, giving it a decidedly more positive tinge ('really changed $L O A D S^{\prime}$ ). Susanne, in turn, takes care to reduce its positive implications ('but not A:LL that'). Similar discrepancies emerge in the same conference with respect to a range of other topics, such as being able to sleep ('CH: can sleep-SW: now you sleep well') or Susanne's contact with her family ('SW: that turned out nicely with the family-CH: it's only Silke and Anna who I have contact with and Tina once in a while'). Given these rather less distinct improvements, the professionals' assessment nevertheless turns out fairly positive:

[5] Susanne 1906-7

SW: .hh ACtually now if I take a close lookyou've atTAIned nearly all the goals haven't you,

As our conversational data clearly show, termination conferences are built on favourable descriptions of a client and their welfare progress as a base and a justification for leaving care. The function of positive categorisation is to reduce the gap between actual and target conditions that was so definitive of the client status up to then, thereby making further support seem unnecessary. The description of personal progress in positive terms thus produces the relevant identity for the setting: the earlier negative categorisations are invalidated, thereby deconstructing the role of a client in such a way that the termination of the service provision seems to be the obvious consequence of the client's development.

\section{Displaying progress and responsibility over larger time periods}

As noted, undoing negative categorisations is connoted with a strong sense of change over time. Positive assessments in a termination conference tend to address the personal development not only since the last meeting, but preferably over larger time periods (e.g. 'by now'). The discontinuation of a long-term welfare provision implies the need for a retrospective assessment comprising the entire progress of the young person. We find in our termination conferences various statements in this respect:

[6] Susanne 1426-8

SW: that last year you took giant steps.

$<$ quietly $>$ that's seven-league-boots you were wearing there. $=$ 
$=$ seriously $->$

[7] Lena 733-7

SW: like right,

when I remember how I MET you-

you TOOK giant steps,

there's no putting it any other way,

[8] Güley 2240-2; 2634-8

CR: however that of $\mathrm{c}-$

like I said that got BETter;

that was r:eally diSAStrous before,

(...)

SW: what was it mrs. (Heinert) said last summer-

she('s) $<<$ loudly $>$ really PROUD of Güley; $>$

because they (really) accomplished S:O: much,

now if I tink of (think of)-

how we met-

Referring to larger time distances makes the clients' personal progresses appear more distinct. A summary review not only serves to make clearly visible the laudable progress the welfare provision has triggered ('giant steps'; 'seven-league-boots'; 'accomplished S:O: much'), but also highlights the attribution of creatorship for that progress ('you took'; 'you were wearing'; 'PROUD of Güley'). In retrospect, the success of improvement is no longer credited to the professional quality of the service provision, but primarily ascribed to the client herself, thereby underlining once more her independence and responsibility concerning her own life.

\section{Termination conferences as places of conflict}

Discontinuation of care is generally unfavoured by the adolescent clientele: the withdrawal of support at a point in their life already characterised by suspense and insecurity appears to them as a manifest threat. Their obvious reaction thus consists of the attempt to maintain their clientele identity - at least to a certain degree. Accordingly, the adolescents in the conferences studied opt for claiming further need for support, such as Susanne, who fears that she will be without financial backing once her welfare is ended:

[9] Susanne 1435-42

SW: now what do you still HAVE to; 
what $(\mathrm{d}=$ you $/ \mathrm{d}=$ she $)$ still have to achieve-

[(I don't know actually);

CH: [I have to ahm: (-) settle (-) A:gencie:s. (---)

at the: for example JOB centre (too),

an:d .hhh ORphan's pensio:n and child benefits and all that stuff $=\mathrm{h}$,

(--) an:d = h uh: WHO will give me money afterwards,

Or Lena, who also claims more support:

[10]

Lena 513-26 (slightly simplified)

$\mathrm{CH}$ : well I want-

$<<$ slowly $>$ THREE months worth of follow-up care by ANne

Katarina Hollmann; $>$

$<<$ in a singsong, becoming faster $>$ so that she can still explain

EVErything to me;

that I'm not alone;

that I (can b)-

when I have PROBlems that I can call her-

and I still want to go to \{name of institution\}; >

I want to: (-) take part in the:::: afternoons,

take part in the creative afternoons,

$\mathrm{AND}=\mathrm{h}$ some other great something;

AND I want to come along for \{name of a TV talkshow -

We find comparable expressions of a need for support in the other termination conferences. Most often, these concern basic issues such as settling questions of financing or dealings with official agencies, school or work. From the adolescents' perspectives, the service provision cannot be terminated-or not quite at this point in time. Their reactions are thus contrary to the actual aim of the termination conferences. Correspondingly, the emerging conflict is characterised by the same pattern: on the one side, the clients casting themselves as in continuing need of further support; on the other, the professionals arguing for the contrary position. Accordingly, the two sides pursue rather different strategies: while the clients try for consolidation and validation of their claims, these are in turn rebutted by the professionals - either by pointing towards the laudable progress achieved up to now or by indicating the client's fault in its lack, as other data in our study strongly suggest (for reasons of space, this result can merely be hinted at this point). Both sides' rhetoric is correspondingly sensitive with regard to the issues at stake: The professionals take great care not only to put the progress achieved in a positive light ('LOADS'; 'giant steps'; ' $g$ ood PATH'; etc.), but, in addition, they invalidate the need for further support as put forward by the clients: 
[11] Lena 1086-96

SW: $\quad$ so [now what I've understood from this is-

CR: $\quad\left[()^{-}\right.$

SW: you're still inseCU:re (.) about how to deal with the job centre, you'll be needing a little asSIStance there, when until that's all [DONE,

$\mathrm{CH}:$

[three months-

SW: you'd still like to have Anne (.) by your side-

= just so IF: something comes upyou (.) right,

you: can still ASK her about it-

and so that Anne might possibly come along one more time;

Different forms of minimisation, which mass in this particular example (' $a$ little'; 'you'd like to'; 'IF something comes up'; 'you can still ASK'; 'might possibly') reduce the clients' expressed need into a mere eventuality of marginal impact. In contrast, the clients can highlight their deficits by mitigating the professionals' positive assessments, such as Susanne in excerpt [4]. The adolescents know, of course, of the intent to terminate the service provision in the particular conference, but still attempt to delay the point of termination as much as possible. The termination is thus considered as a matter of fact, while its schedule is treated as a matter of negotiation. Both parties agree to this starting point, which allows them to represent their individual perspective while searching a workable compromise. In cases in which such a compromise does not seem to be attainable, however, professionals may revert to the constraints of their institutional background, such as, for instance, in Susanne's case:

[12] Susanne 1948-56

SW: h. and I THINK, that we: (--) that sa you know Saskia has accompanied you this far-

that now you really can take your own steps by yourself.

not imMEDiately,

not tomorrow, (1.0)

and we do want to prepare this well, $=$

$=$ BUT $(--)<<$ becoming quiet, drawled $>$ this support will be terminated here. $>$ 


\section{Social work between professionalism and social construction}

In view of the analyses presented above, terminating a period of welfare provision turns out to be a demanding procedure. In order to legitimate the ending of a professional-client relationship, proof is called for that the initial goal of the service provision has successfully been attained. Such proof is substantially based upon the clients' capacities for solving their everyday problems, pointing to an independent and responsible lifestyle, which, in turn, reflects the effectiveness of institutional welfare provision.

This conclusion, however, as our analyses have showed, fundamentally rests on the descriptions and reasoning by the practitioners, which make up a homogenous pattern of declientification that transforms the individual client into a mature and self-reliant citizen no longer dependent on care. The most prominent element of this pattern is a levelling out of the differences between actual and target states in the client's character and lifestyle by positive depiction and evaluation of their personal development. While establishing the clients' role is fundamentally marked by efforts of making visible an institutionally workable, deficient identity, declientification, in contrast, works to neutralise these need-related categories so carefully constructed before. The rhetoric employed is subtle throughout. By means of rhetoric upgrading (concerning the positive development of the client) and downgrading (concerning the need for further support) applied to larger time periods, professionals create a picture of the client that can be flexibly adapted to the purposes of the individual setting.

Being obliged to angle their reasoning to the requirements of the setting, the practitioners have to position themselves in an intricate web of different premises and various, sometimes conflicting institutional aims. The necessity of taking into account at all points the institutional constraints and financial matters that are connected to any service provision apparently influences the form and direction professional assessments can take. While the communicative format of declientification is governed by identical patterns, it is also embedded in an institutional context that allows for its exploitability. It can be adopted in order to declare successful termination even in cases in which satisfaction levels are low at best. The use of declientification formats thus is apparently never quite separable from the frameworks of institutional social work. Factually justified and strategically embellished accounts become hard to tell apart. Treating personal development as a success seems to be the preferred declientification strategy, as it is in line with professional reasoning relative to the institutionally set objectives. However, holding a client responsible for their progress may also entail their accountability for insufficient advancement. It is worthwhile 
to note that such an accounting for failed institutional help is possible only when it is the client him- or herself, rather than the quality of institutional service provision, who is subject to evaluation and proof (for a theory-based description of this pattern, see Lipsky (1980, p. 152)).

We can therefore conclude that professionals in care planning conferences are not simply objectively judging experts. Rather, they are constructors of clientele identities that are modelled by a given institutional casting mould. Pithouse and Atkinson (1988) were among the first to show that 'cases' need to be 'told'; that is, institutionally informed selections need to be made from a host of options in order to reduce social work's inherent uncertainties. The information provided by the client and accumulated during encounters needs to be bestowed with sense through rhetorical practices, which do not need to name the case explicitly, but rather make it professionally palpable. We show that, in the same way as individuals have to be made visible as cases, as legitimate clients of institutional service provision, a reverse version is needed that enables the professionals to delegitimate the client's status and to substantiate their development into a mature and self-reliant citizen. The necessity of selecting elements for depiction inevitably makes any description biased and incomplete, while, at the same time, it is treated as an objective reference for the inferences to be made. Seen from this perspective, the objectivity of 'social facts' is thus essentially the product of the communication they are established in. Language, we can argue, does not only serve to provide an objective perspective on social facts; rather, it constitutes social facts by means of social description.

Furthermore, we see that depicting 'reality' in interaction turns the distinction between an object (what is talked about) and a subject (who talks about it) into a problem. Objects are what subjects make of them by their choice of description. 'Objectiveness' turns out to be no more than a product of definitions caught up in the circularity of wanting to ascertain facts while incessantly constituting them. These definitions are only reliable as long as they are mutually shared by the participants. In order to successfully establish client identities, evidence (in terms of consistent, uncontradictory accounts) and consensus (in terms of common agreement among participants) have proven normative for descriptions and decisions alike. However, if evidence primarily proves to be the product of professionally dominated descriptions and consensus is sufficient if formed among practitioners alone, we are left with the impression of a close and selfimmunising practice, which, in its self-referentiality, is hard to penetrate and near impossible to dismantle.

As we hope to have shown, social workers are faced with the necessity of framing their interactions in a way that they create a productive setting for their decision making within a given institutional aim. Interactions serve as a connecting and transforming element between the institutional context and the handling of singular 'cases'. Correspondingly, ethnomethodological 
conversation analysis focuses on this element of translation rather than on either side. Thus, it can help us understand the complex nature of how professionals transform context into effective practices, matching it with the available possibilities and resources for the individual case. CA's perspective is indispensable if one aims to describe the hidden rationalities of everyday institutional practice. It can unveil the unquestioningly accepted constructions used by professionals and replace the straightforward descriptions of social work practice by a different vantage point that, taking seriously what is out there, can make evident the contradictions and ambivalences that govern child welfare provision in the context on the termination of residential care.

\section{Annex: Transcript notation}

\section{Speakers}

$\begin{array}{ll}\text { CR } & \text { carer } \\ \text { CH } & \text { child/young person } \\ \text { HS } & \text { head of service provider } \\ \text { HW } & \text { head of welfare office } \\ \text { SW } & \text { social worker }\end{array}$

\section{Other conventions}

$\begin{array}{ll}(.) & \text { micro pause } \\ (-) & \text { pause (one dash approximately } 0.25 \text { seconds) } \\ (1.0) & \text { pause (in seconds) } \\ () & \text { unintelligible utterance } \\ (\text { yes }) & \text { uncertain utterance } \\ ((\text { laughs })) & \text { context remarks } \\ <<\text { loudly }>> & \text { remarks describing the utterance (including scope) } \\ . h \text { hh } & \text { inbreath } \\ : & \text { stretching of phonemes } \\ \text { WELL } & \text { capitals: emphasis } \\ \text { and [so } & \\ \quad \text { [okay } & \text { overlap } \\ \text {; } & \text { voice falls } \\ - & \text { voice falls slightly } \\ \text {, } & \text { voice unchanging } \\ ? & \text { voice rises slightly }\end{array}$




\section{Acknowledgements}

This article is part of a study on Reflexive Care Planning conducted in 2005-2008 and funded by the German Research Foundation.

\section{References}

Antaki, C., Young, N. and Finlay, M. (2002) 'Shaping clients' answers: Departures from neutrality in carestaff interviews with people with a learning disability', Disability \& Society, 17(4), pp. 435-55.

Baur, D., Finkel, M., Hamberger, M. and Kühn, A. (2002) Leistungen und Grenzen von Heimerziehung [Benefits and Limitations of Residential Care], 2nd edn, Stuttgart, Kohlhammer.

Bergmann, J. (1985) 'Flüchtigkeit und methodische Fixierung sozialer Wirklichkeit: Aufzeichnungen als Daten der interpretativen Soziologie' ['Volatility and methodological fixation of social reality according to the data records of interpretive sociology'], in W. Bonß and H. Hartmann (eds), Entzauberte Wissenschaft: Zur Relativität und Geltung soziologischer Forschung [Disenchanted Science: Relativity and Application of Sociological Research], Göttingen, Schwarz.

Brown, P. and Levinson, S. (1987) Politeness: Some Universals in Language Usage, Cambridge, Cambridge University Press.

Bull, R. and Shaw, I. (1992) 'Constructing causal accounts in social work', Sociology, 26(4), pp. 635-49.

Cedersund, E. and Säljö, R. (1993) 'Bureaucratic discourse, conversational space and the concept of voice', Semiotica, 97(1), pp. 79-101.

Erickson, F. and Shultz, J. (1982) The Counselor as Gatekeeper: Social Interaction in Interviews, New York, Academic Press.

Garfinkel, H. (1967) Studies in Ethnomethodology, Englewood Cliffs, Prentice-Hall.

Hall, C., Parton, N., Juhila, K. and Pösö, T. (2003a) 'Conclusion: Yes, but is this of any use?', in C. Hall, N. Parton, K. Juhila and T. Pösö (eds), Constructing Clienthood in Social Work and Human Services: Interaction, Identities, and Practices, London, Jessica Kingsley Publishers.

Hall, C., Parton, N., Juhila, K. and Pösö, T. (eds) (2003b) Constructing Clienthood in Social Work and Human Services, London, Jessica Kingsley Publishers.

Hall, C., Slembrouck, S. and Sarangi, S. (2006) Language Practices in Social Work: Categorisation and Accountability in Child Welfare, London, Routledge.

Hasenfeld, Y. (1972) 'People processing organizations: An exchange approach', American Sociological Review, 37(3), pp. 256-63.

Heritage, J. (1984) Garfinkel and Ethnomethodology, New York, Polity Press.

Hitzler, S. and Messmer, H. (2010) 'Group decision-making in child welfare and the pursuit of participation', Qualitative Social Work, 9(2), pp. 205-26.

Holstein, J. A. (1992) 'Producing people: Descriptive practice in human service work', in G. Miller (ed.), Current Research in Occupations and Professions 7, Greenwich, JAI Press.

Hydén, L. (1994) 'The social worker as a moral worker: Applying for money: The moral encounter between social workers and clients', in B. Gunnarsson, P. Linell and B. Nordberg (eds), Text and Talk in Professional Contexts, Uppsala, ASLA. 
Jefferson, G. (2004) 'Glossary of transcript symbols with an introduction', in G. H. Lerner (ed.), Conversation Analysis: Studies from the First Generation, Amsterdam, Benjamins.

Kurz-Adam, M., Frick, U. and Köhler, M. (2002) 'Wer steuert die Heimerziehung? Anmerkungen und empirische Befunde zur Qualitätsdiskussion in den Erziehungshilfen' ['Who controls residential care? Observations and empirical findings on the quality debate in child welfare'], Zentralblatt für Jugendrecht, 89(6), pp. 201-11.

Lindsay, M. (1994) 'Towards a theory of careism: Discrimination against young people in care', Seen and Heard, 4, pp. 27-38.

Lipsky, M. (1980) Street-Level Bureaucracy: Dilemmas of the Individual in Public Services, New York, Russel Sage Foundation.

Maunders, D., Liddell, M. and Green, S. (1999) Young People Leaving Care and Protection: A Report to the National Youth Affairs Research Scheme, ed. by National Youth Affairs Research Scheme, Australian Clearinghouse for Youth Studies, available online at www.acys.utas.edu.au/nyars/N17.html.

Mendes, P. and Moslehuddin, B. (2004) 'Graduating from the child welfare system: A comparison of the UK and Australian leaving care debates', International Journal of Social Welfare, 13(4), pp. 332-9.

Messmer, H. (2007) Jugendhilfe zwischen Qualität und Kosteneffizienz [Youth Services between Quality and Cost], Wiesbaden, VS-Verlag für Sozialwissenschaften.

Messmer, H. and Hitzler, S. (2007) 'Die soziale Produktion des Klienten: Hilfeplangespräche in der Kinder- und Jugendhilfe' ['The social production of clients: care planning talks in child and youth services'], in W. Ludwig-Mayerhofer, O. Behrend and A. Sondermann (eds), Aushandeln, Verstehen, Klassifizieren: Akteure in der Sozialverwaltung und ihre Klienten [Negotiation, Understanding, Classifying: Actors in Social Services and their Clients], Opladen/Farmington Hills, Budrich.

Mik-Meyer, N. (2007) 'Interpersonal relations or jokes of social structure? Laughter in social work', Qualitative Social Work, 6(1), pp. 9-26.

Modellprogramm Fortentwicklung des Hilfeplanverfahrens (2003) Hilfeplanung als Kontraktmanagement? Erster Zwischenbericht des Forschungs- und Entwicklungsprojektes 'Hilfeplanung als Kontraktmanagement' [Care Planning as Contract Management? First Progress Report of the Research and Development Project 'Care Planning as Contract Management'], München, Eigenverlag.

Nikander, P. (2008) 'Working with transcripts and translated data', Qualitative Research in Psychology, 5(3), pp. 225-31.

Osvaldsson, K. (2004) 'On laughter and disagreement in multiparty assessment talk', Text, 24(4), pp. 517-45.

Pithouse, A. and Atkinson, P. (1988) 'Telling the case: Occupational narrative in a social work office', in N. Coupland (ed.), Styles of Discourse, London, Croom Helm.

Pluto, L. (2007) Partizipation in den Hilfen zur Erziehung: Eine empirische Studie [Participation in Child Welfare: An Empirical Study], München, DJI-Verlag.

Sacks, H. (1992) Lectures on Conversation, ed. by G. Jefferson, Oxford, Blackwell.

Sacks, H., Schegloff, E. and Jefferson, G. (1974) 'A simplest systematics for the organization of turn-taking for conversation', Language, 50(1), pp. 696-735.

Sandermann, P., Urban, U. and Schruth, P. (2007) 'Unter Druck und Zwang. Zur staatlichen Existenzgefährdung junger Volljähriger' ['Under pressure and coercion: Existence risks of young adults produced by State into conditions'], Sozial Extra, 31(7/ 8), pp. 12-17. 
Sarangi, S. (1998) 'Interprofessional case construction in social work: The evidential status of information and its reportability', Text, 18(2), pp. 241-70.

Selting, M., Auer, P., Barden, B., Bergmann, J., Couper-Kuhlen, E., Günthner, S., Quasthoff, U., Meier, Ch., Schlobinski, P. and Uhmann, S. (1998) 'Gesprächsanalytisches Transkriptionssystem' ['Conversation analysis transcription system'], Linguistische Berichte, 173, pp. 91-122.

Stein, M. (2005) Resilience and Young People Leaving Care, available online at www.jrf .org.uk/sites/files/jrf/185935369x.pdf.

Stein, M. (2006) 'Research review: Young people leaving care', Child \& Family Social Work, 11(3), pp. 273-9.

Thiersch, H. (1999) 'Politik, Jugendhilfe, Heimerziehung' ['Policy, youth services, residential care'], in H. Colla, T. Gabriel, S. Millham, S. Müller-Teusler and M. Winkler (eds), Handbuch Heimerziehung und Pflegekinderwesen in Europa [Manual Residential Care and Foster Care in Europe], Neuwied-Kriftel, Luchterhand.

West, A. (1995) You're on Your Own: Young People's Research on Leaving Care, London, Save the Children.

Wiesner, R. (2007) 'Was will das SGB VIII? Und was sieht das SGB II für junge Volljährige vor?' ['What does the SGB VIII do? And what is the aim of the SGB II regarding young adults?'], Sozial Extra, 31(7/8), pp. 18-21. 